\title{
Evolution and maintenance of stigma-height dimorphism in Narcissus. I. Floral variation and style-morph ratios
}

\author{
ANGELA M. BAKER* ${ }^{*}$, JOHN D. THOMPSON $+\&$ SPENCER C. H. BARRETT† \\ $\dagger$ Department of Botany, University of Toronto, 25 Willcocks Street, Toronto, Ontario, Canada M5S $3 B 2$ and \\ $\$$ Centre d'Ecologie Fonctionnelle et Evolutive, CNRS, 1919 Route de Mende, 34293, Montpellier Cedex 5, France
}

\begin{abstract}
An unusual stylar dimorphism occurs in Narcissus, a plant genus of insect-pollinated Mediterranean geophytes. To determine the characteristics of the sexual polymorphism, we investigated floral variation in 46 populations of $N$. assoanus (section Jonquillae) and 21 populations of $N$. dubius (section Tazettae) in SW France. Flowers possess two stamen levels in each morph that occupy slightly different positions within the floral tube. In long-styled plants (L-morph), the stigma is located within or slightly above the upper-level stamens, whereas in short-styled plants (S-morph) the stigma is placed well below the lower-level stamens. The stigma-height dimorphism is distinct from heterostyly because the reciprocity of stigma and anther positions in the two style morphs is only weakly developed and there are no differences between the style morphs in pollen size or production. In both species, mean stigma-anther separation is much greater in the S-morph than the L-morph. In $N$. assoanus, population style-morph ratios vary from isoplethy (1L:1S) to L-biased, whereas in $N$. dubius they are usually strongly L-biased or occasionally contain only the L-morph. Populations fixed for the S-morph, or with S-biased morph ratios, were not observed. In N. assoanus, style-morph ratios were associated with population size: large continuous populations always exhibited 1:1 morph ratios, whereas smaller, fragmented populations were often L-biased. This pattern was not evident in $N$. dubius. We argue that biased style-morph ratios largely result from morph-specific differences in assortative mating.
\end{abstract}

Keywords: Amaryllidaceae, disassortative mating, heterostyly, morph ratios, population size, stigma-height dimorphism.

\section{Introduction}

Sexual polymorphisms involving discrete variation in the length or position of the style are reported from many unrelated flowering plant families (Webb \& Lloyd, 1986; Barrett et al., 2000a,b). The most common stylar polymorphism is heterostyly which Darwin (1877) first examined in detail and has been the focus of a great deal of subsequent research (reviewed in Ganders, 1979; Barrett, 1992; Richards, 1997). Heterostylous populations have two (distyly) or three (tristyly) floral morphs which differ reciprocally in the placement of stigmas and anthers (Lloyd \& Webb, 1992a). Another, less well known, stylar polymorphism is characterized by discrete variation in the position of the stigma but little or no reciprocal positioning in anther placement between the

*Correspondence. E-mail: abaker@botany.utoronto.ca two style morphs. Populations exhibiting stigma-height dimorphism comprise two floral morphs, one in which the stigma is at the same level as the stamens or protrudes beyond them (long-styled or L-morph) and the other in which the stigma is located below the stamens (short-styled or S-morph). Some authors recognize stigma-height dimorphism as distinct from heterostyly (Charlesworth \& Charlesworth, 1979; Ganders, 1979; Jernstedt, 1982; O'Brien \& Calder, 1989; Barrett \& Richards, 1990; Lloyd \& Webb, 1992a; Arroyo \& Dafni, 1995; Barrett et al., 1996), whereas others view the polymorphism as part of the variation encompassed within heterostyly (Philipp \& Schou, 1981; Dulberger, 1992; Richards, 1997 and pers. comm.). Unfortunately, there have been few detailed studies of species with stigma-height dimorphism to assess the nature of floral variation and the evolutionary and functional relationships between this polymorphism and heterostyly. This is unfortunate because stigma-height dimorphism plays 
an important role in some models of the evolution of distyly (Lloyd \& Webb, 1992b).

Stigma-height dimorphism occurs commonly in Narcissus (Amaryllidaceae), a genus of approximately 40 species of insect-pollinated geophytes largely native to the Mediterranean basin. Dulberger (1964 and unpubl. data) reported stigma-height dimorphism in N. tazetta populations from Israel (and see Arroyo \& Dafni, 1995). Using controlled crosses she demonstrated that self-incompatibility was not of the heteromorphic type, although the inheritance of style length conformed to the single-locus two-allele control common in distylous species, with the allele for short styles dominant. Stigma-height dimorphism has subsequently been documented in several additional species from three sections of the genus (Apodanthae, Jonquillae, Tazettae) by Barrett et al. (1996). Despite the widespread distribution of stigma-height dimorphism in Narcissus, heterostyly only occurs in distylous $N$. albimarginatus of section Apodanthae (J. Arroyo \& S. C. H. Barrett, 2000) and tristylous N. triandrus of section Ganymedes (Barrett et al., 1997; Sage et al., 1999), and the evolutionary relationships between stigma-height dimorphism, distyly and tristyly are unclear. In their model of the evolution of heterostyly, Lloyd \& Webb (1992b) suggested that stigma-height dimorphism is rare in flowering plants because it may be difficult to maintain (and see Charlesworth \& Charlesworth, 1979). According to this view, selection rapidly favours the evolution of discrete anther-height variation in populations with stigmaheight dimorphism and hence the polymorphism represents a transient stage in the evolution of heterostyly (and see O'Brien \& Calder, 1989). However, in Narcissus the contrasting frequencies and phylogenetic distributions of the two polymorphisms are not in accord with this model and further studies are clearly warranted to explain the evolutionary stability of stigma-height dimorphism in the genus.

In large distylous populations with frequent sexual recruitment, equilibrium morph ratios are generally isoplethic (1L:1S) and result from disassortative mating governed by the heteromorphic incompatibility system typical of most heterostylous plants (reviewed in Ganders, 1979). However, in N. tazetta (Dulberger, 1964) and N. triandrus (Barrett et al., 1997) both interand intramorph pollinations are fully compatible and morph ratios are governed by the influence of floral morphology on the relative fitness of the morphs as female and male parents (Barrett et al., 1996). Intramorph mating in Narcissus spp. provides opportunities for variation in levels of assortative mating in the style morphs resulting in populations with biased morph ratios or those containing only a single morph. Unlike heterostylous species with conventional heteromorphic incompatibility, a wide range of style-morph ratios is therefore predicted in natural populations of Narcissus spp.

We examine these issues in populations in $N$. assoanus and $N$. dubius, two species from different sections of the genus which occur in SW France. Preliminary observations suggested that both species exhibit stigma-height dimorphism but that the patterns of sex-organ variation differ in association with several features of their floral biology that might be expected to influence pollination and mating. Here we report the findings of a comparative study in which the goal was to provide insights into the evolution and maintenance of stigma-height dimorphism. In this paper we ask the following questions: (i) what are the patterns of sex-organ variation in natural populations of $N$. assoanus and $N$. dubius and do the two species exhibit a true dimorphism for stigma height? (ii) are there morph-specific differences in pollen size and production in either Narcissus spp. (a feature commonly associated with distyly)? (iii) what style-morph ratios characterize populations of $N$. assoanus and $N$. dubius and what factors might explain any differences observed both within and between species? In a companion paper (Baker et al., 2000), we examine fitness components of the style morphs in an effort to understand the selective mechanisms maintaining the polymorphism and the contrasting style-morph ratios in the two species reported in this paper.

\section{Materials and methods}

\section{Natural history of Narcissus assoanus and $\mathrm{N}$. dubius}

Narcissus assoanus (section Jonquillae) is a diminutive species, approximately $10-15 \mathrm{~cm}$ in height, that is widespread in S Spain and SW France. In SW France, it typically occurs in meadows and stony pastures on limestone from sea level to $700 \mathrm{~m}$ altitude. Plants produce a single inflorescence with one to three deepyellow flowers with prominent coronas and long floral tubes. In SW France the vast majority of plants produce a single flower. Flowering time depends on altitude and usually occurs from late February to April.

Narcissus dubius (section Tazettae) is larger (20$25 \mathrm{~cm}$ ), with inflorescences of one to seven white flowers also with prominent coronas and long floral tubes. In SW France flowering begins in mid-February and ends in late March. The species has a more restricted distribution, occurring primarily along the east coast of S Spain and in SW France at less than $300 \mathrm{~m}$ altitude and in some areas is found in sympatry with $N$. assoanus. Narcissus dubius occurs almost exclusively in stony, limestone garrigues and on or around cliff 
faces. Narcissus assoanus is pollinated by butterflies, hawkmoths and solitary bees, whereas $N$. dubius is pollinated by hawkmoths, flies and solitary bees.

\section{Patterns of sex-organ variation}

To establish whether $N$. assoanus and $N$. dubius exhibit a true dimorphism for stigma height, we sampled populations of both species for floral measurements at peak flowering (late February-March for N. dubius; March-April for $N$. assoanus). All sampling was undertaken in the Languedoc-Roussillon region of SW France in an area bounded by the Rhône River to the east and the city of Perpignan near the France-Spain border to the west. In each population, flowers were sampled randomly from throughout the entire population with care taken to not sample more than one inflorescence from dense clumps which may have arisen via bulb fragmentation (particularly in N. dubius). Floral measurements were made on a single mature flower from at least 45 randomly selected individuals from 15 $N$. assoanus and $10 \mathrm{~N}$. dubius populations. These populations were chosen from throughout the range of stylemorph ratios revealed from our survey (see below). The following floral traits were measured to $0.01 \mathrm{~mm}$ using digital callipers: flower length, stigma height, and the distance to the top and bottom of the upper- and lowerlevel stamens. For each stamen level, the distance to the middle of the anthers was calculated by taking the mean of the distance to the top and bottom of the anthers within a level. All measurements were made from the top of the ovary (Fig. 1).

To account for the influence of flower size on patterns of sex-organ variation we adjusted the measurements of stigma height and upper- and lower-stamen height for flower length. We first performed an analysis of covariance (ANCOVA) using JMP statistical software (SAS, 1994), in which population and style morph were treated as main effects and flower length was treated as a covariant. Secondly, two- and three-way interaction terms were eliminated from the model using backward elimination if they contributed less than $5 \%$ of the variation in organ height (cf. Sokal \& Rohlf, 1995). Finally, we adjusted organ position as follows: adjusted organ position $=$ organ position $-b$ (flower length mean flower length), where $b$ represents the slope of the line of organ position plotted against flower length. This process accounts for variation in organ position caused by variation in flower size among individuals but does not significantly alter the value of mean organ position. Differences in mean adjusted organ position between the morphs for populations of each species were then assessed using ANOVA with population and style morph as main effects.

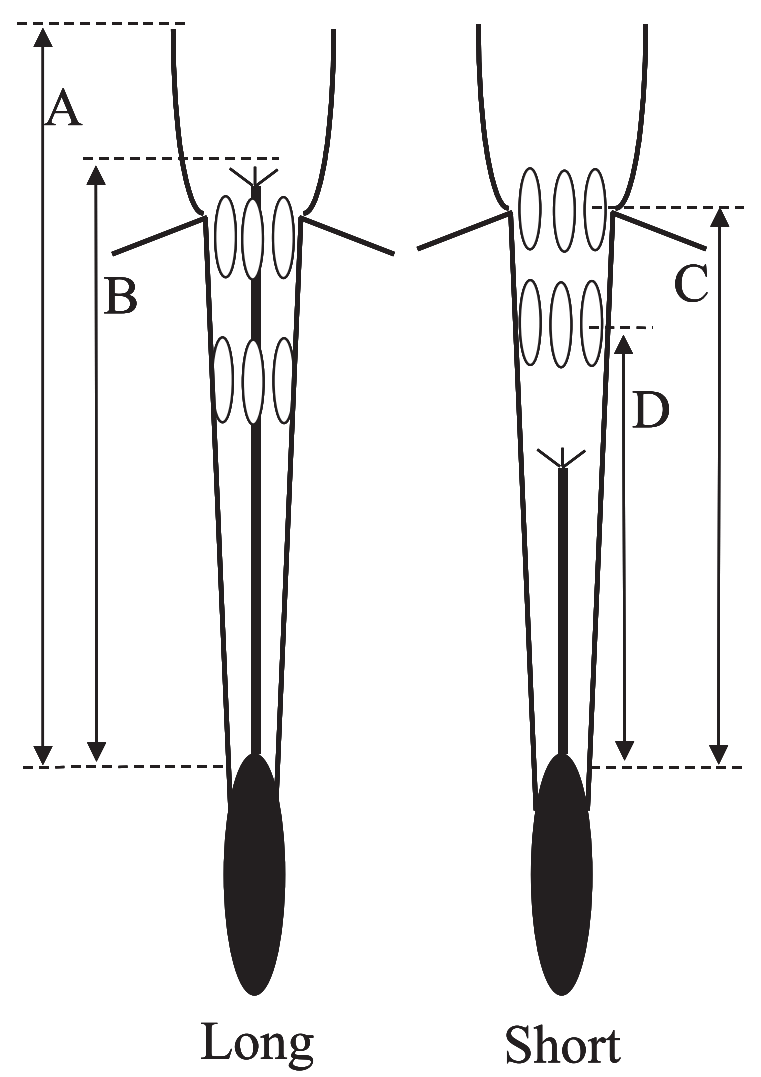

Fig. 1 Floral measurements made on flowers of Narcissus assoanus and $N$. dubius. The illustration shows the L- and S-morphs of $N$. assoanus drawn to scale based on average measurements from all populations. Flower length (A) and stigma height (B) were measured directly; the distances to the middle of the upper-level stamens (C) and the middle of the lower-level stamens (D) were calculated (see text for details).

\section{Pollen characteristics}

All three anthers from a given stamen level were collected prior to anthesis and placed in Eppendorf sample tubes. Anthers were allowed to dry and fully dehisce before the tube was filled with $70 \%$ ethanol. Pollen size and production were quantified using an electronic Elzone 282 particle counter with a $190 \mu \mathrm{m}$ aperture. Each sample was vortexed for $15 \mathrm{~s}$ to dislodge pollen grains from anthers and $0.5 \mathrm{~mL}$ was removed from the tube and added to a vial containing $24.5 \mathrm{~mL}$ of saline solution $(0.5 \% \mathrm{NaCl})$. The particle counter counted the number of particles in $0.25 \mathrm{~mL}$ samples, assigned them to logarithmic size classes, and calculated the mean geometric size of the pollen grains. For each pollen sample, mean estimates of pollen size and number are based on four $0.25 \mathrm{~mL}$ subsamples. We counted pollen samples from 12 plants of each style morph in one $N$. assoanus population and 12 and 10 plants of the 
L- and S-morph, respectively, from a $N$. dubius population. Pollen size and number were analysed separately in each population using a two-way ANOvA with style morph and stamen level as main effects.

\section{Surveys of style-morph ratios}

Floral measurements established that populations of both $N$. assoanus and $N$. dubius were dimorphic for stigma height. Plants could be classified as either L- or S-styled based on the placement of the stigma with respect to the two stamen levels. We conducted an extensive survey to determine the relative frequencies of the two style morphs in populations of each species. During spring in years 1996-98 we sampled 46 and 21 populations of $N$. assoanus and $N$. dubius, respectively, for style-morph ratios. Pooled goodness-of-fit $G$-tests were calculated to determine whether pooled morph ratios differed significantly from $1 \mathrm{~L}: 1 \mathrm{~S}$. We also calculated $G_{\text {heterogeneity statistics to test for heterogeneous }}$ morph ratios among populations. For each population, two or three independent estimates of population size were made and the average value was taken. Data on style-morph ratios and individual sizes for populations in the survey are available upon request from A.M.B.

\section{Results}

\section{Variation in sex-organ position in natural populations}

Populations of $N$. assoanus and $N$. dubius both exhibit a stigma-height dimorphism despite considerable variation in the relative positions of stigmas and anthers among individuals within each population (Fig. 2). With the exception of monomorphic populations of $N$. dubius fixed for the L-morph, there is a clear discontinuity in style length between individuals of the L- and S-morph. The data presented in Fig. 2 were not adjusted to account for flower size and therefore some of the variation undoubtedly results from developmental or environmental influences. However, despite these sources of variability, a fundamental dimorphism in stigma height is evident. A two-way ANOva on the data obtained from all populations with style morph and population as main effects indicated that mean stigma height $(\mathrm{mm})$ was significantly different between the style morphs in both species $(N$. assoanus: L-morph $=17.43$, $\mathrm{SE}=0.082 ; \quad \mathrm{S}-\mathrm{morph}=8.94, \quad \mathrm{SE}=0.079 ; \quad F_{1,692}=$ 3956.66, $\quad P<0.001 ; \quad N$. dubius: $\quad$ L-morph $=15.61$, $\mathrm{SE}=0.095 ; \quad \mathrm{S}-\mathrm{morph}=9.49, \quad \mathrm{SE}=0.215 ; \quad F_{1,314}=$ $295.07, P<0.001)$. When sex-organ position is adjusted to account for differences in flower size, the ANOvA results were not qualitatively different (Table 1). In all analyses of variation in sex-organ position, there were no significant differences in the results obtained between the adjusted or raw data. Consequently, all subsequent $F$-values we present are those using data that were adjusted to account for flower size.

Although mean stigma height was strongly differentiated between the style morphs in both species, the corresponding positions of the two stamen levels differed much less, although consistent differences were evident when data were examined across populations. In a two-way ANOVA with morph and population as main effects, mean positions of upper- and lower-level stamens $(\mathrm{mm})$ were significantly lower in the floral tube of the L-morph compared to the S-morph in both species (Table 1). In both species, mean stamen position differs significantly among populations and the interaction between population and style morph was significant in $N$. dubius but not in $N$. assoanus (Table 2). The two stamen levels in the L-morph were more strongly differentiated from one another than the corresponding stamen levels of the S-morph, especially in $N$. assoanus. This can be seen by inspection of Fig. 1 which is drawn to scale using mean values obtained from $N$. assoanus populations.

In both species, flowers of the L-morph typically have stigmas positioned within or slightly above the upperlevel stamens. In contrast, stigmas are located well below the lower-level stamens in the S-morph (Fig. 2). These contrasts in the relative position of stigmas and anthers result in striking differences in the degree of herkogamy exhibited by the style morphs (Fig. 3). Over the 15 sampled populations of $N$. assoanus, mean stigmaanther separation in the S-morph was 5.4 times greater than in the L-morph. The same pattern was also observed in $N$. dubius, where the degree of stigma-anther separation between the style morphs was even greater. Mean stigma-anther separation in $N$. dubius was 33 times greater in the S-morph than in the L-morph averaged over the seven dimorphic populations sampled. In $N$. dubius most flowers of the L-morph have their stigmas positioned within the upper-level stamens (Fig. 2).

\section{Variation in pollen size and number}

We found no evidence for morph-specific or stamenlevel differences in pollen size in either of the species under study $(N$. assoanus: L-morph $=21.86 \mu \mathrm{m}, \mathrm{SE}=$ $0.081 ; \mathrm{S}-\mathrm{morph}=21.70 \mu \mathrm{m}, \mathrm{SE}=0.126 ; F_{3,44}=0.7225$, $P=0.5440 ; N$. dubius: $\mathrm{L}-\mathrm{morph}=25.89 \mu \mathrm{m}, \mathrm{SE}=0.100$; S-morph $=25.33 \mu \mathrm{m}, \quad \mathrm{SE}=0.475 ; \quad F_{3,40}=0.5230, \quad P=$ 0.6690). Also, there were no significant differences between style morphs or stamen levels in the number of pollen grains produced in either species $(N$. assoanus: $\mathrm{L}$-morph $=64912$ pollen grains per flower, $\mathrm{SE}=2260$; 

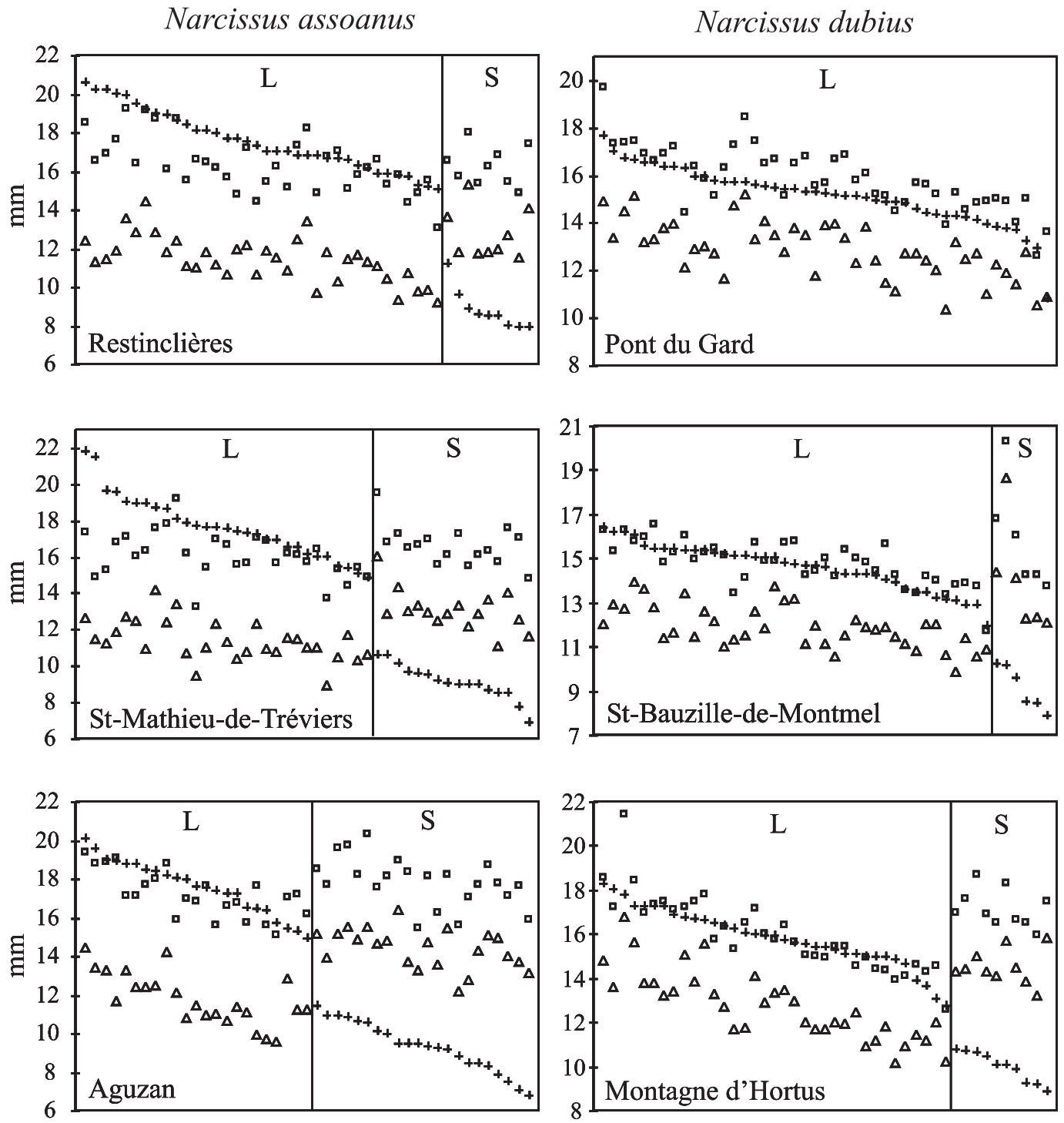

Fig. 2 The range of variation in stigma height $(+)$, height of upper-level stamens $(\square)$ and lower-level stamens $(\triangle)$ among long- (L) and short-styled (S) individuals from three populations of Narcissus assoanus and N. dubius from SW France. Individual flowers are ranked by stigma height. Sex-organ position was not adjusted to account for flower size.

$\mathrm{S}-\mathrm{morph}=64875, \mathrm{SE}=3743 ; F_{3,44}=0.3926, P=0.7589$; $N$. dubius: $\mathrm{L}-\mathrm{morph}=59113, \mathrm{SE}=2733 ; \mathrm{S}$-morph $=$ $50355, \mathrm{SE}=3609 ; F_{3,40}=1.3810, P=0.2625$ ).

\section{Style-morph ratios in natural populations}

All 46 populations of $N$. assoanus sampled were dimorphic for style length. Style-morph ratios varied from 1L:1S ( $N=25$ populations) to L-biased ( $N=21$ populations). There was no relation between style-morph ratios (frequency of S-morph) and the degree of S-level organ reciprocity (mean difference in height of lower anthers of L-morph and stigmas of S-morph) among the
15 populations for which detailed floral measurements were undertaken $(r=0.20, P=0.476)$. No populations with a statistically significant excess of the S-morph were observed. A significant excess of the L-morph was evident when the morph-ratio data were pooled across all populations $(\mathrm{L}-\mathrm{morph}=0.62, \mathrm{~S}$-morph $=0.38$; $G_{\text {pooled }}=204.56$, d.f. $\left.=1, P<0.001\right)$ and there was significant heterogeneity among population morph ratios $\left(G_{\text {het }}=44603.18\right.$, d.f. $\left.=45, P<0.001\right)$. Of the 21 populations of $N$. dubius sampled for morph ratios, 15 were dimorphic and the remaining six were monomorphic, containing only the L-morph. Dimorphic populations were strongly L-biased and, like $N$. assoanus, 
Table 1 The position of sexual organs in 15 and seven dimorphic populations, respectively, of Narcissus assoanus and N. dubius. Mean values $(\mathrm{mm})$ are given for stigma height, upper-stamen height and lower-stamen height. Sample sizes were $450 \mathrm{~L}$ - and 272 S-styled flowers for $N$. assoanus and $275 \mathrm{~L}$ - and 53 S-styled flowers for $N$. dubius. Sex-organ position was adjusted to account for differences in flower size and significant differences were assessed using ANOva (see text for details). There are statistically significant differences between the style morphs in stigma height, upper stamen height, and lower stamen height in both species

\begin{tabular}{|c|c|c|c|c|c|c|}
\hline & \multicolumn{3}{|c|}{ Narcissus assoanus } & \multicolumn{3}{|c|}{ Narcissus dubius } \\
\hline & Long & & Short & Long & & Short \\
\hline $\begin{array}{l}\text { Stigma height } \\
\text { Standard error } \\
\text { Range }\end{array}$ & $\begin{array}{l}17.43 \\
0.080 \\
11.29-22.20\end{array}$ & $* * *$ & $\begin{array}{l}8.94 \\
0.071 \\
6.54-12.50\end{array}$ & $\begin{array}{l}15.62 \\
0.081 \\
12.04-20.01\end{array}$ & $* * *$ & $\begin{array}{l}9.38 \\
0.180 \\
3.11-12.38\end{array}$ \\
\hline $\begin{array}{l}\text { Upper stamen height } \\
\text { Standard error } \\
\text { Range }\end{array}$ & $\begin{array}{l}16.34 \\
0.053 \\
12.34-20.40\end{array}$ & $* * *$ & $\begin{array}{l}16.85 \\
0.061 \\
13.38-19.63\end{array}$ & $\begin{array}{l}15.42 \\
0.058 \\
13.15-17.96\end{array}$ & $*$ & $\begin{array}{l}15.79 \\
0.171 \\
13.10-18.19\end{array}$ \\
\hline $\begin{array}{l}\text { Lower stamen height } \\
\text { Standard error } \\
\text { Range }\end{array}$ & $\begin{array}{l}11.62 \\
0.053 \\
7.51-15.72\end{array}$ & $* * *$ & $\begin{array}{l}13.34 \\
0.067 \\
9.61-15.76\end{array}$ & $\begin{array}{l}12.20 \\
0.064 \\
9.25-15.46\end{array}$ & $* *$ & $\begin{array}{l}13.28 \\
0.184 \\
10.67-16.44\end{array}$ \\
\hline
\end{tabular}

$* P<0.05,{ }^{* *} P<0.01,{ }^{* * *} P<0.001$.

Table 2 Two-way ANova of stigma height, and position of upper and lower stamens in 15 Narcissus assoanus and seven N. dubius populations. Sex organ position was adjusted to account for differences in flower length (see text for details)

\begin{tabular}{|c|c|c|c|c|c|c|c|c|}
\hline \multirow[b]{2}{*}{ Source } & \multicolumn{4}{|c|}{ Narcissus assoanus } & \multicolumn{4}{|c|}{ Narcissus dubius } \\
\hline & d.f. & MS & $F$ & $P$ & d.f. & MS & $F$ & $P$ \\
\hline \multicolumn{9}{|l|}{ Stigma height } \\
\hline Morph & 1 & 9999.99 & 3627.22 & $0.0001 * * *$ & 1 & 1290.07 & 411.50 & $0.0001 * * *$ \\
\hline Population & 14 & 14.93 & 5.30 & $0.0018 * *$ & 6 & 7.01 & 1.96 & 0.2161 \\
\hline Morph $\times$ population & 14 & 2.85 & 1.48 & 0.1146 & 6 & 3.57 & 2.78 & $0.0119^{*}$ \\
\hline \multicolumn{9}{|l|}{ Upper stamen height } \\
\hline Morph & 1 & 47.84 & 37.51 & $0.0001 * * *$ & 1 & 15.09 & 7.08 & $0.0288^{*}$ \\
\hline Population & 14 & 5.57 & 4.31 & $0.0049 * *$ & 6 & 14.69 & 6.43 & $0.0197^{*}$ \\
\hline Morph $\times$ population & 14 & 1.29 & 1.25 & 0.2345 & 6 & 2.28 & 1.53 & 0.1673 \\
\hline \multicolumn{9}{|l|}{ Lower stamen height } \\
\hline Morph & 1 & 490.05 & 298.81 & $0.0001 * * *$ & 1 & 60.44 & 19.34 & $0.0035^{* *}$ \\
\hline Population & 14 & 6.09 & 3.63 & $0.0108^{*}$ & 6 & 16.00 & 4.38 & $0.0478^{*}$ \\
\hline Morph $\times$ population & 14 & 1.68 & 1.51 & 0.1011 & 6 & 3.66 & 4.25 & $0.0004 * * *$ \\
\hline
\end{tabular}

$* P<0.05,{ }^{* *} P<0.01,{ }^{* * *} P<0.001$.

there was also a significant excess of the L-morph when data were pooled across populations (L-morph $=$ $0.93, \quad$ S-morph $=0.07 ; \quad G_{\text {pooled }}=1208.23, \quad$ d.f. $=1$, $P<0.001)$. Significant heterogeneity among population morph ratios was also evident $\left(G_{\text {het }}=52.45\right.$, d.f. $=20, P<0.001)$.

In $N$. assoanus, the observed morph-ratio variation among populations was nonrandomly distributed over the geographical region sampled (Fig. 4). On the other hand, in $N$. dubius, with the exception of a small concentration of four monomorphic populations located along the Gardon river valley north of Nîmes, there was no obvious geographical pattern to morph-ratio variation (Fig. 5). Populations of $N$. assoanus closest to the coast occurring in the garrigue landscape surrounding Montpellier were smaller and more isolated from one another. All exhibited strongly L-biased morph ratios. In contrast, populations further inland and away from Montpellier were more likely to have isoplethic morph ratios. This geographical pattern was associated with habitat fragmentation and population size. Inland populations tended to be much larger than those closer to Montpellier where suitable habitats for the species are more restricted in area. In particular, populations in the NW portion

(C) The Genetical Society of Great Britain, Heredity, 84, 502-513. 
(a) Narcissus assoanus

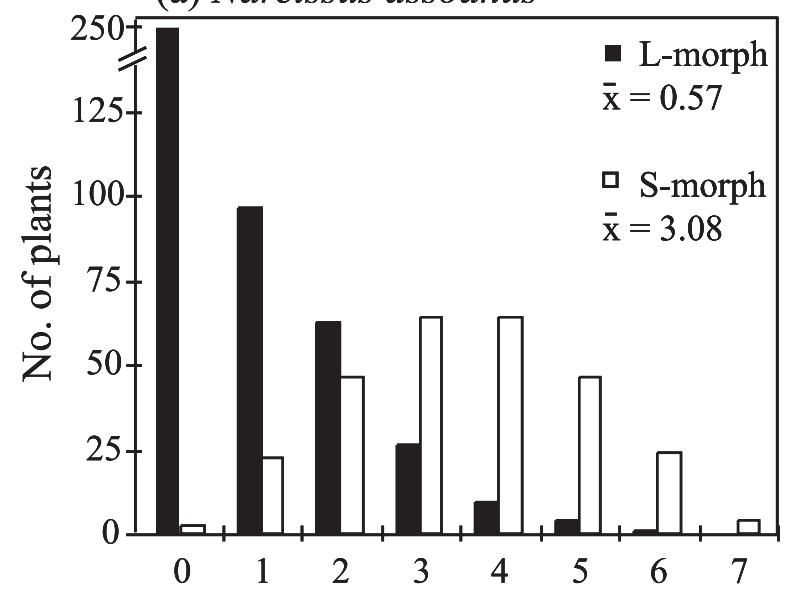

(b) Narcissus dubius

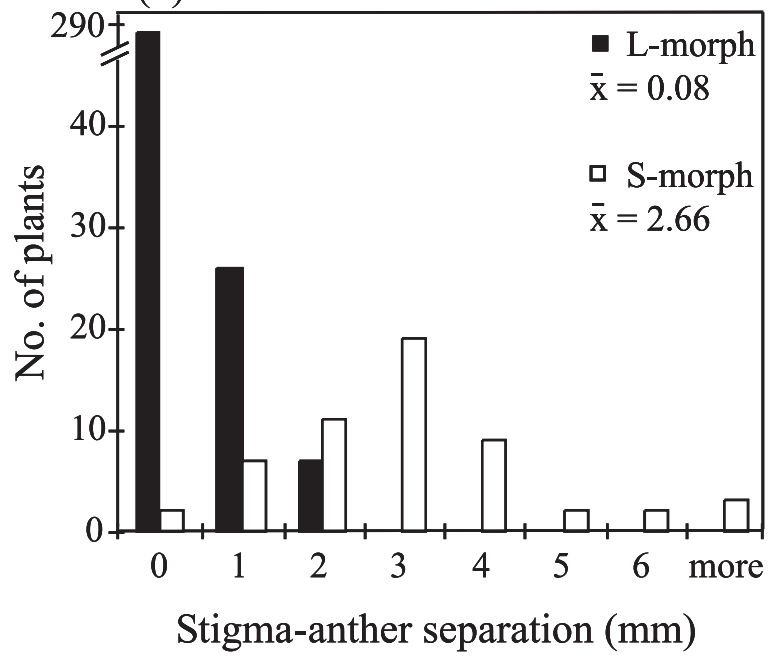

Fig. 3 Stigma-anther separation (herkogamy) in dimorphic populations of Narcissus assoanus and N. dubius. Stigmaanther separation was calculated for 450 and 262 flowers of the L- and S-styled morphs, respectively, from 15 N. assoanus populations and 315 and 55 flowers of the L- and S-morphs, respectively, from eight $N$. dubius populations. Stigma-anther separation was calculated by determining the difference between stigma height and the nearest anther. Stigma-anther separation is 0 when the stigma is located within a stamen level.

of the region sampled on 'Le Causse de Blandas' and 'Le Causse du Larzac' limestone plateaux were very large in size and always exhibited isoplethic morph ratios. Figure 6(a) illustrates the relation between population size and morph ratio in $N$. assoanus. Whereas smaller populations display variable morph ratios, very large populations were always isoplethic. In $N$. dubius there was no association between population size and morph ratio (Fig. 6b). However, populations of this species never attain the size of the larger $N$. assoanus populations.

\section{Discussion}

The major findings of this study are that populations of $N$. assoanus and $N$. dubius possess a sexual polymorphism involving discrete variation in style length. Minor differences in the positions of the two stamen levels within a flower also occur. Population surveys revealed different patterns of variation in style-morph ratios in the two species, although L-biased morph ratios commonly occur in both. Here, we begin by reviewing what is known about stigma-height dimorphism in plants and address the question of whether the two Narcissus species should be considered heterostylous. We then discuss functional aspects of the dimorphism and consider the selective mechanisms that may account for the contrasting patterns of morph-ratio variation revealed in our surveys.

\section{Stigma-height dimorphism and its relationship to heterostyly}

Reports of stigma-height dimorphism are infrequent in other genera of flowering plants. They include: Anchusa spp. (Dulberger, 1970; Philipp \& Schou, 1981) and Lithodora spp. (S.C.H. Barrett, J.D. Thompson \& D. Manicacci, unpubl. data) in the Boraginaceae; Linum grandiflorum (Darwin, 1877; Dulberger, 1992) in the Linaceae; Chlorogalum angustifolium (Jernstedt, 1982; Barrett et al., 2000b) in the Liliaceae; Epacris impressa (O'Brien \& Calder, 1989) in the Epacridaceae; Kalmiopsis leachiana (Barrett et al., 2000a) in the Ericaceae; and Anigozanthos humilis (S.D. Hopper, pers. comm.) in the Haemodoraceae. In common with dimorphic Narcissus spp., populations of these taxa are generally characterized by a bimodal distribution of style length but little or no differentiation in stamen position in the two style morphs. Several genera with stigma-height dimorphism occur in families in which heterostyly is common (e.g. Boraginaceae and Linaceae), raising the question of whether the polymorphism represents a transitional stage in the evolution of distyly (and see Lloyd \& Webb, 1992a,b). However, in other cases (e.g. Liliaceae and Ericaceae) heterostyly is absent from the families and the evolution of stigma-height dimorphism appears to involve isolated events of unknown adaptive significance.

Heterostyly has been defined as 'a genetically determined polymorphism in which the morphs differ in the sequence of heights at which the anthers and stigmas are presented within their flowers' (Lloyd \& Webb, 1992a, p. 152). The morphological features of $N$. assoanus and $N$. dubius flowers match this description well. However, Lloyd \& Webb (1992a) elaborated this definition further to emphasize that the position of stigmas and anthers in 
Fig. 4 Geographical distribution of style-morph ratios in 46 populations of Narcissus assoanus in SW France. The frequency of the L- (black) and S-morphs (white) are indicated for each population. Smaller populations occurring in areas disturbed by urbanization and agriculture tended to have L-biased morph ratios, whereas larger populations further from Montpellier were always isoplethic.

Fig. 5 Geographical distribution of style-morph ratios in 21 populations of Narcissus dubius in SW France. The frequency of the L- (black) and S-morphs (white) are indicated for each population.
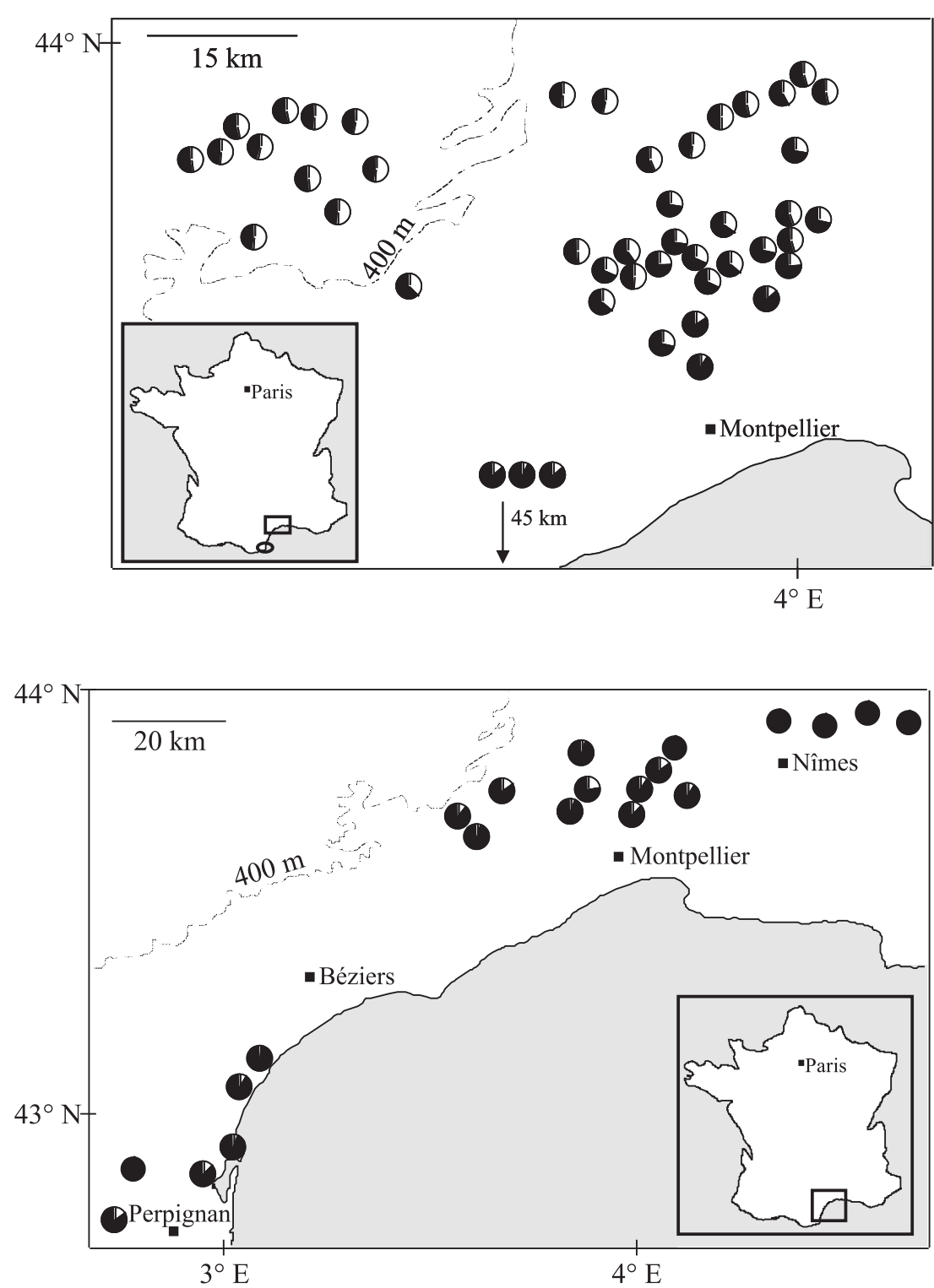

the floral morphs must differ in a reciprocal manner. Indeed this reciprocal herkogamy (Richards, 1986, p. 262) was considered by Lloyd \& Webb (1992a) to be a defining feature of heterostyly and on this basis they distinguished distyly from stigma-height dimorphism using Narcissus as an example of the latter (also see Ganders, 1979, p. 608). We agree with this perspective, which differs from the view held by Dulberger (1992) and Richards (1997 and pers. comm.) who advocate a broader view of heterostyly which includes species without reciprocal herkogamy. Our more restricted definition of heterostyly excludes species that lack a clear reciprocal correspondence between stigmas and anthers. Additionally, although pollen size and production commonly differ between the style morphs in heterostylous species, there is no evidence of morph- specific differences in pollen characters of $N$. assoanus or $N$. dubius. Based on these findings, we prefer to classify $N$. assoanus and N. dubius as nonheterostylous. As discussed further in Baker et al. (2000), other features of the reproductive systems of $N$. assoanus and $N$. dubius are atypical for heterostylous plants. We believe these distinguishing features merit the recognition of stigmaheight dimorphism as a plant sexual polymorphism distinct from yet functionally similar to heterostyly.

\section{Functional consequences of sex-organ deployment}

Casual observations of the two style morphs in $N$. assoanus and $N$. dubius indicated that stamen levels were located at similar positions within the floral tube. 
(a) Narcissus assoanus

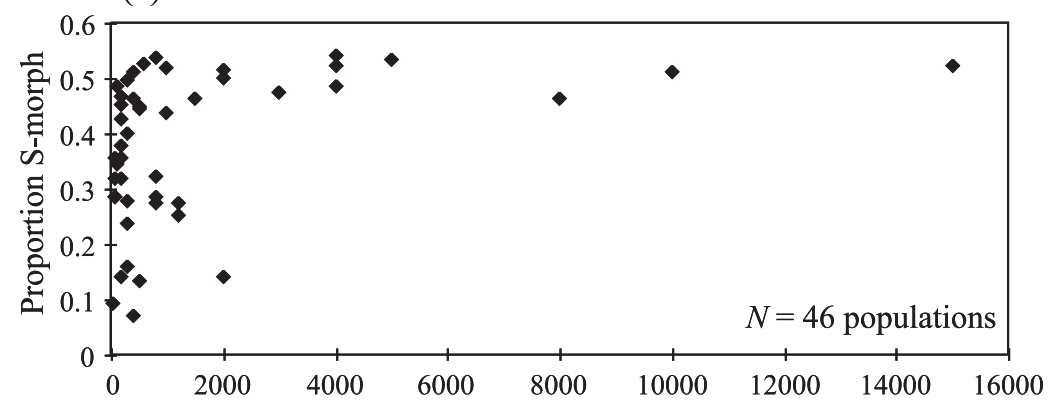

(b) Narcissus dubius

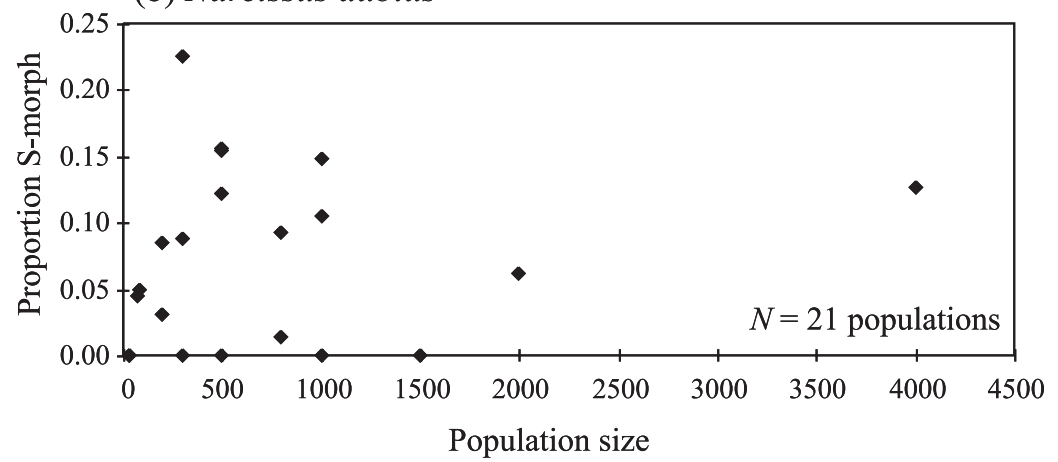

Fig. 6 The relation between the proportion of short-styled plants in a population and its size in (a) Narcissus assoanus, and (b) N. dubius.
However, our detailed measurements revealed subtle differences between the style morphs in both species. Are these differences of functional significance for pollination and mating? This seems unlikely in the case of the upper-level stamens, where there is less than $0.5 \mathrm{~mm}$ difference between the morphs in their position in both species. In fact, within most populations there was no significant difference between the height of the upperlevel stamens in the two morphs (nine of 15 populations for $N$. assoanus; four of seven for $N$. dubius following $t$-tests, results not shown). It is difficult to imagine that this small difference in mean height of upper-level stamens has significant morph-specific influences on pollen dispersal, given the large amount of variation among individual plants in their position (Fig. 2).

The difference between style morphs in the position of lower-level stamens was much greater than for upperlevel stamens and hence may have functional significance. This difference was evident in both species but was more pronounced in $N$. assoanus [mean difference ( $\mathrm{mm})$ : 1.7 in $N$. assoanus and 1.0 in $N$. dubius]. Lower-level stamens in the L-morph were always positioned significantly lower in the floral tube relative to the corresponding stamen level of the S-morph. Interestingly, this difference was a consistent feature of all populations we sampled in both species, suggesting that the positioning may influence pollen dispersal. It is possible that the lower-level stamens are under disruptive selection in the two style morphs. Selection to reduce the height of these stamens in the L-morph may increase male fertility because of more proficient pollen dispersal to stigmas of the S-morph. In contrast, selection to increase the height of lower-level stamens in the S-morph may reduce self-pollination and self-interference and also increase the effectiveness of pollen dispersal to stigmas of the L-morph. Because upper-level stamens in both morphs probably transfer most of their pollen to stigmas of the L-morph, selection would be more likely to maintain them at a similar position corresponding to the height of stigmas in the L-morph.

The most striking morphological difference between the style morphs of both species involves the degree of herkogamy that they exhibit. Stigmas and anthers are in close proximity in flowers of the L-morph, whereas there is considerable spatial separation in the S-morph. There is substantial evidence that the degree of herkogamy has important functional consequences for mating patterns, especially selfing rates (see Belaoussoff \& Shore, 1995 and references therein). Plants with weakly developed herkogamy usually experience more self-pollination than those with well separated sex organs. Indeed, studies of self-pollen deposition in caged individuals of $N$. assoanus demonstrated that flowers of the L-morph often have upwards of 200 self pollen grains deposited on stigmas through autonomous self-pollination, whereas flowers of the S-morph always have fewer than 
15 (A.M. Baker, J.D. Thompson \& S.C.H. Barrett, unpubl. data). Similar results were also obtained in $N$. tazetta by Arroyo \& Dafni (1995), a species that exhibits the same morph-specific differences in herkogamy.

What are the likely functional consequences of different rates of autonomous self-pollination in the style morphs? As yet there is no clear answer to this question. Experimental studies have demonstrated that $N$. assoanus is moderately self-sterile, whereas $N$. dubius is highly self-compatible. These differences between the two species are reflected in contrasting selfing rates in natural populations (Baker et al., 2000). Yet comparative data on the mating systems and female fertility of the style morphs of both species failed to detect significant morph-specific influences on maternal selfing rates or seed-set (Baker et al., 2000). This suggests that although the quantity and composition (self vs. outcrossed) of pollen deposited on stigmas of the style morphs are likely to be different, postpollination mechanisms may act to filter heterogeneous pollen loads resulting in the similar maternal fitness components that we observed.

\section{Factors influencing morph-ratio variation}

Our surveys of $N$. assoanus and N. dubius in SW France revealed a wide range of style-morph ratios ranging from isoplethy to populations fixed for the L-morph. This finding is consistent with the results of earlier studies of N. tazetta (Arroyo \& Dafni, 1995) in Israel and N.papyraceus in S Spain (Barrett et al., 1996). In these surveys, similar patterns of variation were reported, with many populations exhibiting biased morph ratios and monomorphic populations fixed only for the L-morph. A survey of nine populations of five dimorphic Narcissus species, including two populations of N. assoanus from S Spain, also revealed L-biased morph ratios in all populations (Barrett et al., 1996). Collectively, these results raise the question of why Narcissus populations often exhibit L-biased morph ratios?

Barrett et al. (1996) and Baker et al. (2000) developed pollination and mating models, respectively, that can explain biased style-morph ratios in Narcissus populations with a stigma-height dimorphism. The models indicate that L-biased morph ratios will occur if there are higher levels of assortative mating in this morph compared to the S-morph. Morph-specific differences in sex-organ deployment in $N$. assoanus and $N$. dubius suggest that this is likely to occur. Although upper-level anthers of the L-morph are well positioned to transfer pollen to stigmas of other plants of this morph, the high degree of herkogamy in the S-morph reduces the likelihood of proficient assortative pollen transfer. Most pollen transferred to S-stigmas probably originates from the lower-level anthers of the L-morph, which are positioned below the corresponding anther level in the $\mathrm{S}$-morph. Morph-specific differences in the ratio of assortative to disassortative mating resulting from asymmetric pollen transfer within and between the style-morphs can explain the L-biased morph ratios observed in Narcissus spp. (Baker et al., 2000).

Why are monomorphic populations of Narcissus spp. almost always fixed for the L-morph? If offspring from plants of the S-morph are largely the products of disassortative mating they will mostly be heterozygous $(S s)$ at the locus controlling style length, assuming that inheritance is of the single-locus control demonstrated in $N$. tazetta (Dulberger, 1964) and found in most heterostylous species (Ganders, 1979). Heterozygosity at the $S$-locus is also promoted in populations with L-biased morph ratios. This is because plants of the S-morph are more likely to mate with individuals of the L-morph because of the high abundance of the latter. Hence homozygous short-styled plants $(S S)$ should occur rather infrequently in most populations of Narcissus spp. because of low levels of assortative mating in this morph and L-biased morph ratios. Interestingly in her studies on the inheritance of style-length in $N$. tazetta, Dulberger (1964) found no homozygous short-styled plants despite the absence of intrinsic barriers to intramorph mating. Elsewhere, a similar finding was also reported by Schou \& Philipp (1984) in their genetic studies of Anchusa officinalis, a species that exhibits stigma-height dimorphism, intramorph compatibility and strongly L-biased morph ratios.

The apparent rarity of homozygous plants of the S-morph restricts opportunities for S-monomorphy. This is because heterozygous plants of the S-morph that found new populations will always segregate both morphs, thus guaranteeing establishment of stylar dimorphism. In contrast, L-morph $(s s)$ founders will only produce long-styled offspring, giving rise to populations monomorphic for this morph. Thus according to this hypothesis the contrasting occurrence of L- vs. S-morph monomorphism arises because of morphspecific differences in mating and the dominance relationships at the $S$-locus governing stylar dimorphism.

However, two alternative hypotheses could also explain the absence of S-monomorphy in Narcissus spp. Strong selection against homozygous $(S S)$ plants because of inbreeding depression could prevent the establishment of monomorphic populations composed of the S-morph. In this regard, Richards (1997, p. 284) has argued that S-morph-linked recessive lethality is 'a pervasive feature of heterostylous plants' (and see Richards, 1998), but unfortunately the experimental 
evidence for this phenomenon is only mixed at best (Shore \& Barrett, 1985; Eckert \& Barrett, 1993). Nevertheless, it would be worth investigating this possibility through controlled crosses of short-styled plants. Finally, it is possible that plants of the S-morph are poor at establishing populations because their concealed stigmas are only accessible to long-tongued pollinators which may be less inclined to visit isolated plants. According to this hypothesis, fertility selection favours the L-morph as a founding morph because its sex organs are more accessible to short-tongued generalist pollinators that might be more likely to visit small, newly established populations. We have not been able to detect morph-specific differences in female fertility in established populations of $N$. assoanus or $N$. dubius, but it would certainly be worth comparing patterns of seedset in experimental monomorphic populations composed of the L- vs. the S-morph to test this hypothesis.

Populations with equal frequencies of the two style morphs were commonly observed in $N$. assoanus, indicating that stigma-height dimorphism can result in equivalent levels of disassortative mating. This finding is significant because it is an assumption for Lloyd \& Webb's (1992a,b) model for the evolution of distyly from stigma-height dimorphism. The floral morphologies of isoplethic populations were similar to those exhibiting biased morph ratios and there was no evidence of a greater reciprocal correspondence in anther and stigma positions that might favour symmetrical disassortative mating. Isoplethic populations tended to occur in the less disturbed landscapes and particularly on the upland limestone plateaux northwest of Montpellier where populations were all very large. It is possible that the frequency and composition of pollinators visiting isoplethic vs. nonisoplethic populations differ in ways that influence pollen transfer and mating patterns. Observations of pollinator visits to $N$. assoanus indicate that the primary visitors are butterflies (Gonepteryx cleopatra), solitary bees (Anthophora spp.) and day-flying hawkmoths (Macroglossum stellatarum) but as yet we have not been able to determine whether visitation patterns differ between populations with contrasting style-morph ratios. Elsewhere it has been argued that differences in the types of pollinators visiting populations of $N$. tazetta (Arroyo \& Dafni, 1995), N. papyraceus and N. triandrus (Barrett et al., 1996) may explain the striking patterns of morphratio variation that these species also exhibit. To distinguish how different pollinators might influence pollination and mating, measurements of pollen transfer and male fertility are required.

Isoplethic style-morph ratios were not observed in $N$. dubius and the S-morph was generally either rare or absent from populations. Strongly biased morph ratios in this species probably reflect the mating consequences of weak disassortative mating compared with $N$. assoanus. In common with many plant species that flower in very early spring (Schemske et al., 1978), N. dubius is highly self-compatible. Not unexpectedly, populations of this species exhibit higher selfing rates than the selfsterile $N$. assoanus (Baker et al., 2000). Higher selfing in $N$. dubius is also probably influenced by opportunities for geitonogamy because of the multiflowered inflorescences of this species. It is possible that weak disassortative mating may be destabilizing the stigma-height dimorphism in $N$. dubius resulting in the gradual elimination of the S-morph from many populations. Selection against the S-morph may also be occurring in hill populations of $N$. tazetta (Arroyo \& Dafni, 1995) and N. papyraceus (Barrett et al., 1996), two other members of section Tazettae.

In conclusion, stigma-height dimorphism represents a curious and perplexing floral design. It seems probable that the polymorphism functions to promote more proficient pollen transfer among plants in a manner similar to heterostyly. However, how disassortative pollen transfer is achieved, at least in some populations, without well developed sex-organ reciprocity is unclear. The wide range of style-morph ratios that characterize populations of Narcissus spp. suggests that the patterns of pollen transfer within and between style morphs vary considerably. Detailed studies of the pollination biology of populations with contrasting style-morph ratios should provide insights into how this occurs.

\section{Acknowledgements}

We thank Jan Molinar, Henri Michaud and Max Debussche for help in locating populations; Lawrence Harder and Anne Worley for valuable discussion and assistance in the field; Linley Jesson, Bill Cole and John Richards for helpful comments on the manuscript. This work was funded by an operating grant from NSERC to S.C.H.B. and a grant from CNRS to J.D.T. A.M.B. was supported by graduate scholarships from NSERC and the Ontario Government.

\section{References}

ARROYO, J. AND DAFNI, A. 1995. Variation in habitat, season, flower traits, and pollinators in dimorphic Narcissus tazetta L. (Amaryllidaceae) in Israel. New Phytol., 129, 135-145.

ARRoYo, J. AND BARRETT, S. C. H. 2000. Discovery of distyly in Narcissus (Amaryllidaceae). American Journal of Botany, in press.

BAKER, A. M., THOMPSON, J. D. AND BARRETT, S. C. H. 2000. The evolution and maintenance of stigma-height dimorphism in Narcissus. II. Fitness comparisons between style morphs. Heredity, 84, in press. 
BARRETT, S. C. H. (ed.) 1992. Evolution and Function of Heterostyly. Springer, Berlin.

BARRETT, S. C. H. AND RICHARDS, J. H. 1990. Heterostyly in tropical plants. Mem. N. Y. Bot. Gard., 55, 35-61.

BARRETT, S. C. H., LlOYD, D. G. AND ARroyo, J. 1996. Stylar polymorphisms and the evolution of heterostyly in Narcissus (Amaryllidaceae). In: Lloyd, D. G. and Barrett, S. C. H. (eds) Floral Biology. Studies on Floral Evolution in AnimalPollinated Plants, pp. 339-376. Chapman \& Hall, New York.

BARRETT, S. C. H., COLE, W. W., ARROYO, J., CRUZAN, M. B. AND LLOYD, D. G. 1997. Sexual polymorphisms in Narcissus triandrus (Amaryllidaceae): is this species tristylous? Heredity, 78, 135-145.

BARRETT, S. C. H., JESSON, L. K. AND BAKER, A. M. 2000a. The evolution and function of stylar polymorphisms in flowering plants. Annals of Botany, in press.

BARRETT, S. C. H., BAKER, A. M. AND JESSON, L. K. 2000b. Mating strategies in monocotyledons. In: Wilson, K. L. and Morrison, D. (eds) Systematics and Evolution of Monocots, pp. 56-267. CSIRO Publishing, Australia.

BELAOUSSOFF, S. AND SHORE, J. S. 1995. Floral correlates and fitness consequences of mating-system variation in Turnera ulmifolia. Evolution, 49, 545-556.

CHARLESWORTH, D. AND CHARLESWORTH, B. 1979. A model for the evolution of distyly. Am. Nat., 114, 467-498.

DARWIN, C. 1877. The Different Forms of Flowers on Plants of the Same Species. Reprinted in 1986. University of Chicago Press, Chicago, IL.

DUlberger, R. 1964. Floral dimorphism and self-incompatibility in Narcissus tazetta L. Evolution, 18, 361-363.

DUlberger, R. 1970. Floral dimorphism in Anchusa hybrida Ten. Isr. J. Bot., 19, 37-41.

DULBERGER, R. 1992. Floral polymorphisms and their functional significance in the heterostylous syndrome. In: Barrett, S. C. H. (ed.) Evolution and Function of Heterostyly, pp. 41-84. Springer, Berlin.

ECKERT, C. G. AND BARRETT, S. C. H. 1993. The inheritance of tristyly in Decodon verticillatus (Lythraceae). Heredity, 71, 473-480.

GANDERS, F. R. 1979. The biology of heterostyly. N. Z. J. Bot., 17, 607-635.

JERNSTEDT, J. A. 1982. Floral variation in Chlorogalum angustifolium (Liliaceae). Madroño, 29, 87-94.
LLOYD, D. G. AND WEBB, C. J. 1992a. The evolution of heterostyly. In: Barrett, S. C. H. (ed.) Evolution and Function of Heterostyly, pp. 151-178. Springer, Berlin.

LLOYD, D. G. AND WEBB, C. J. 1992b. The selection of heterostyly. In: Barrett, S. C. H. (ed.) Evolution and Function of Heterostyly, pp. 179-207. Springer, Berlin.

O'BRIEN, S. P. AND CALDER, D. M. 1989. The breeding biology of Epacris impressa: Is this species heterostylous? Aust. J. Bot., 37, 43-54.

PHILIPP, M. AND SCHOU, O. 1981. An unusual heteromorphic incompatibility system: Distyly, self-incompatibility, pollen load, and fecundity in Anchusa officinalis (Boraginaceae). New Phytol., 89, 693-703.

Richards, A. J. 1986. Plant Breeding Systems, 1st edn. Allen \& Unwin, London.

RichARDS, A. J. 1997. Plant Breeding Systems, 2nd edn. Chapman \& Hall, London.

RICHARDS, A. J. 1998. Lethal linkage and its role in the evolution of plant breeding systems. In: Owens, S. J. and Rudall, P. J. (eds) Reproductive Biology in Systematics, Conservation and Economic Botany, pp. 71-83. Royal Botanic Gardens, Kew.

SAGE, T. L., STRUMAS, F., COLE, W. W. AND BARRETT, S. C. H. 1999. Differential ovule development following self- and crosspollination in Narcissus triandrus (Amaryllidaceae). Am. J. Bot., 86, 855-870.

SAS 1994. JMP Users Guide, version 3.0.2. SAS Institute, Cary, NC.

SCHEMSKE, D. W., WILLSON, M. F., MELAMPY, M. N., MILLER, L. J., VERNIER, L., SCHEMSKE, K. M. AND BEST, L. B. 1978. Flowering ecology of some spring woodland herbs. Ecology, 59, 351366.

SCHOU, O. AND PHILIPP, M. 1984. An unusual heteromorphic incompatibility system 3 . On the genetic control of distyly and self-incompatibility in Anchusa officinalis L. (Boraginaceae). Theor. Appl. Genet., 68, 139-144.

SHORE, J. S. AND BARRETT, S. C. H. 1985. The genetics of distyly and homostyly in Turnera ulmifolia L. (Turneraceae). Heredity, 55, 167-174.

SOKAL, R. R. AND ROHLF, F. J. 1995. Biometry, 3rd edn. W. H. Freeman, San Francisco.

WEBB, C. J. AND LLOYD, D. G. 1986. The avoidance of interference between the presentation of pollen and stigmas in angiosperms. II. Herkogamy. N. Z. J. Bot., 24, 163-178. 